\title{
Assessment of the nutritional risk of $>53$-year-old men and women in Taiwan
}

\author{
Alan C Tsai ${ }^{1, *}$, Jack MC Chang ${ }^{2}$, Harvey Lin ${ }^{2}$, Yi-Li Chuang ${ }^{2}$, Shu-Hui Lin ${ }^{2}$ and \\ Yu-Hsuan $\operatorname{Lin}^{2}$ \\ ${ }^{1}$ Human Nutrition Program, Department of Environmental Health Science, School of Public Health, \\ The University of Michigan, Ann Arbor, Ml 48109, USA: ${ }^{2}$ Formerly the Taiwan Provincial Institute of Family Planning \\ (TPIFP), now a component of the Bureau of Health Promotion, Department of Health, The Executive Yuen, Taichung, \\ Taiwan, Republic of China
}

Submitted 20 May 2003: Accepted 10 July 2003

\begin{abstract}
Objective: The study was conducted to gain an understanding of the status of potential nutrition risks in $>53$-year-old men and women in Taiwan.

Methods: The study employed a validated nutrition-risk screening questionnaire, the Mini Nutritional Assessment, to assess the potential risk of undernutrition in the elderly population in Taiwan. The questionnaire was translated into the local language, Chinese, and was modified slightly based on cultural considerations. It was administered to 4440 randomly selected subjects by means of face-to-face interviews. The questionnaire included questions on subjective self-evaluations, global parameters, simple dietary assessment and some anthropometric measurements.

Results: Results show that the questionnaire can be used effectively as a tool to screen for individuals who are at risk of undernutrition. It showed that the proportion of the elderly population at risk of nutritional inadequacy is relatively low, but does increase with advanced ageing. The proportion of the elderly considered at high risk of undernutrition was found to increase with age, ranging from $0.88 \%$ for $53-60$-yearold subjects to $1.86 \%$ for subjects aged $60-70$ years, $3.6 \%$ for $70-80$-year-olds and $5.3 \%$ for $>80$-year-old subjects.

Conclusion: The study showed that a simple questionnaire adopted from the Mini Nutritional Assessment can be employed to provide a preliminary screening and to identify individuals who are potentially at increased risk of nutritional inadequacy in the elderly population in Taiwan.
\end{abstract}

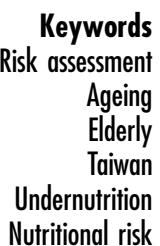

The proportion of the elderly population has been growing rapidly in most countries ${ }^{1}$. This is also true in Taiwan, as the baby boomers born during the post World War II era reach their golden age. In 1958, the proportion of Taiwan's population aged $>60$ years was $4.1 \%$; in 1987 , it was $8.7 \%$; and by the year 2020, it is projected to be $21 \%^{2}$. Ageing is associated with an increase in chronic and degenerative diseases such as heart disease, cancer, hypertension, diabetes, obesity and osteoporosis. These diseases dominate morbidity, mortality, healthcare costs and decreased quality of life. Advanced ageing is also associated with an increased risk of undernutrition, especially protein-energy malnutrition. There are many factors that can contribute to malnutrition. Physiological disorders, physical handicaps, poor dentition, digestive disorders, multiple medications, anorexia and emotional problems such as depression can all impair food intake and lead to undernutrition. Also, other factors such as poverty, food shortage, lack of cooking skills, poor food selection and social isolation or lack of support could all hinder nutrient intake and cause malnutrition. Regardless of the cause, malnutrition is costly. It exacerbates disease, worsens disability and reduces resistance to infection. Ultimately, it increases healthcare costs. However, malnutrition is preventable or correctable. Studies $^{3-5}$ have demonstrated that ensuring adequate nutrition through various intervention programmes for the high-risk elderly can improve their immune competency and reduce the incidence of infection. Nutrition intervention has been shown to be effective in minimising the length of hospital stays, reducing healthcare costs, enhancing quality of life, prolonging life expectancy and, above all, delaying the onset of disability ${ }^{6,7}$. Thus, it is essential to identify individuals who are at risk of malnutrition before they contract diseases, in order to implement proper interventions. The process also needs to be done efficiently and cost-effectively. Unless stopped or corrected in time, a mild setback in health can escalate 
into a downward physical and emotional spiral known as the 'dwindles of ageing', characterised by anorexia, weight loss, depression and social withdrawal and isolation ${ }^{8}$.

A number of nutritional-risk assessment methods have been developed in recent years. The Mini Nutritional Assessment ${ }^{9}$ is a validated nutrition screening tool that uses a set of questions to help health professionals identify individuals at risk for poor nutrition. The Nutrition Screening Initiative uses a DETERMINE checklist to screen for elderly individuals who are at risk for malnutrition ${ }^{10,11}$ The checklist has also been validated as a useful public awareness tool ${ }^{12}$. The present study used a questionnaire adopted from the Mini Nutritional Assessment ${ }^{9}$. We conducted this study to gain an understanding of the status of nutritional risk in the $>53$-year-old population in Taiwan. The study is part of a long-term, longitudinal, cohort research programme designed to investigate the interactive effects of socio-economic and lifestyle factors on the well-being and health status of the elderly population on the island $d^{2,13,14}$.

\section{Methods and materials}

\section{Design and sampling}

The study is part of a longitudinal, cohort ageing research programme involving approximately 4900 subjects in Taiwan, randomly selected from the entire $>53$-year-old population based on nation-wide Household Register Data. The study design consisted of a multistage equal probability sample ${ }^{2}$. The first stage involved dividing the population into 331 townships or primary sampling units (PSUs). The 331 townships were then partitioned into 27 strata of roughly equal population sizes according to three levels of urbanisation, three levels of education and three levels of total fertility rate. This procedure resulted in the selection of 56 PSUs out of 331 townships. In the second stage, blocks of house units called 'lin' were randomly selected within each selected PSU, based on the population size of the PSU relative to the entire population. In the third and final stage, two eligible subjects were selected by systematic random sampling from each of the selected blocks (lin). This sampling process was applied twice, the first time in 1989 to select a total of 4049 subjects who were $>60$ years old and the second time was in 1996 to select a total of 2462 subjects, 50-66 years old. The remaining pool (4915) constituted the sampling size of this study in 1999. This same subject pool has undergone a series of repeated surveys in 1989, 1991, 1993, 1995 and 1999.

As part of a long-term survey study, the questionnaire set was specifically designed to include questions to evaluate subjects' health, nutrition risk and nutritional status, as well as their correlation with socio-economic factors. This study successfully administered the questionnaire survey to 4440 subjects from the 4915 available remaining subjects at the time of the field interviews.

\section{Questionnaire and interviews}

The survey was conducted with a printed questionnaire and was administered by means of individual face-to-face interviews. The nutrition-risk assessment section of the questionnaire was adopted from the Mini Nutritional Assessment, developed by Guigoz et al. ${ }^{9}$. The questionnaire was translated into Chinese and was modified based on cultural considerations. The nutrition component of the questionnaire was repeatedly pre-tested in the field and revised, based on the feedback from both the respondents and the interviewers. The finalised nutrition questionnaire was then incorporated into a large questionnaire set that was also repeatedly pre-tested and revised before being administered. In addition to the questions for nutrition-risk assessment, the nutrition section of the questionnaire set also included other questions aimed at assessing dietary patterns and other nutrition-related parameters. The entire interview process took about $60-90 \mathrm{~min}$ to complete. The nutrition component took approximately $10 \mathrm{~min}$. The nutrition-risk assessment comprised 21 questions (see Appendix). Four of these questions pertained to measuring the subject's height and weight (for computing body mass index, BMI), mid-arm circumference (MAC) and calf circumference (CC) by the interviewer according to standard procedures ${ }^{15}$. The remaining questions focused on global parameters, subjective evaluation and dietary assessment.

Since the original questionnaire ${ }^{9}$ was developed based on Western societies, some modifications were necessary based on cultural and socio-economic considerations. In the global evaluation section, the question about living alone was replaced by 'Do you usually eat alone?', because 'living alone' is rather difficult to define under the current way of living in Taiwan. Many respondents could not decide whether they lived alone. The question on neuropsychological problems was replaced by 'Have you encountered a very sad event within the last 12 months?' since the elderly had difficulty identifying such problems. On the other hand, it was relatively easy to identify sad events such as bereavement that are known to have a severe psychological impact on the elderly and can greatly affect appetite. In the dietary section, the original question on fluid intake was not included because the elderly people had great difficulty working out the amount of liquid consumed and what type of foods to be included in this category. Our questionnaire also did not ask for the number of servings of protein-rich foods or fruits and vegetables because, in Taiwan, people do not have the concept of servings and food is not usually served in such units. Instead, we asked for the consumption frequency of protein-rich foods or fruits and vegetables each day, regardless of the quantity. We also added two questions: 'Do you usually have enough food to eat?' and 'Number of special or restrictive diets your doctor has prescribed for you'. Food availability is a pre-requirement for adequate nutrition. Reduced food availability may affect food 
selection, palatability and intake, and so may contribute to poor health condition. In the area of subjective selfevaluation, we did not ask respondents to compare their overall health status relative to people of the same age. Instead, we asked them more directly 'Do you think you have good health?' We also asked them to compare their health status relative to the condition a year ago.

The questionnaire also included intake frequencies of major food categories including meat, poultry, fish, seafood, eggs, dairy, legumes, vegetables, fruits, cereal foods, dark green or red coloured vegetables, and tea. In addition, it also included a record of the interviewer's subjective opinion of the respondent's body fatness and overall physical condition. The interviewer's observation was mainly for data-confirming or data-verification purposes in assessing the validity of data gathered.

In addition, there were questions relevant to the respondent's nutrition or health status in other sections of the questionnaire. They included data on the subject's general health condition, well-being, chronic diseases, lifestyle (smoking habit, alcohol consumption, physical activity, etc.), long-term medication, intake of healthenhancing products or nutrient supplements, emotional status, economic condition, social activities and support, recreation, family structure, health insurance and health care, and more. Data on these parameters will be published elsewhere.

All interviews were conducted by well-trained and wellexperienced staff of the Institute (TPIFP), assisted by local healthcare workers, who provided scheduling and logistical assistance. For those respondents who could not provide useful information, the interview was carried out with the subject's caregiver or a close relative. Raw data collected were confirmed by a third party through telephone interview. Efforts were made to contact missing subjects for make-up interviews as quickly as possible. Missing or questionable values were completed or corrected through follow-up telephone interviews. All field interviews took place within a period of 12 weeks during the summer of 1999. The study protocol was approved by the Institutional Review Board of the Bureau of Health Promotions of the Department of Health, Taiwan.

\section{Statistical analysis}

Results were statistically analysed with the Statistical Analyses System (SAS Institute, Cary, NC, USA). The frequency distribution for each parameter and correlation analysis (Pearson's correlation coefficient) were performed among major health and nutritional parameters. A probability of $P<0.05$ was chosen to be the level of statistical significance.

\section{Results}

Results are shown in Tables $1-3$ and Figs 1 and 2. The response rate and the number of subjects in each age range
Table 1 Age distribution of the subjects

\begin{tabular}{lccccc}
\hline $\begin{array}{c}53-60 \\
\text { years }\end{array}$ & $\begin{array}{c}60-70 \\
\text { years }\end{array}$ & $\begin{array}{c}70-80 \\
\text { years }\end{array}$ & $\begin{array}{c}>80 \\
\text { years }\end{array}$ & Total \\
\hline Number of subjects & who completed the interview & \\
Male & 459 & 605 & 1036 & 260 & 2360 \\
Female & 451 & 575 & 784 & 270 & 2080 \\
Total & 910 & 1180 & 1820 & 530 & 4440 \\
Total number of cases selected for interview & & & 4915 \\
Response rate (\%) & & & & 90.34 \\
\hline
\end{tabular}

* Total number of randomly selected subjects living at the time of interview, summer of 1999 .

are shown in Table 1 . Of the 4915 remaining available subjects, 4440 (2360 male and 2080 female) completed the interviews. The overall response rate was $90.34 \%$.

Results showed that $8.30 \%$ of the $>53$-year-old men and $8.57 \%$ of the women were underweight $(\mathrm{BMI} \leq 19.0$ $\mathrm{kg} \mathrm{m}^{-2}$ ). Only $1.0 \%$ of males and $3.5 \%$ of females had MAC below the desired value of $21 \mathrm{~cm}$, but $6.61 \%$ of males and $17.55 \%$ of females had CC less than the desired value of $30 \mathrm{~cm}$. A total of $14.75 \%$ of elderly man and $13.80 \%$ of women had lost $\geq 3 \mathrm{~kg}$ of body weight during the last 12 months.

Table 2 Percentage of respondents with 'at-risk' status for each of the parameters surveyed

\begin{tabular}{|c|c|c|c|}
\hline Item & $\left(\right.$ Risk score* $^{\star}$ & $\begin{array}{c}\text { Men } \\
(n=2360)\end{array}$ & $\begin{array}{c}\text { Women } \\
(n=2080\end{array}$ \\
\hline \multicolumn{4}{|l|}{ Anthropometric parameters } \\
\hline $\mathrm{BMl} \leq 19 \mathrm{~kg} \mathrm{~m}^{-2}$ & (2) & 8.30 & 8.57 \\
\hline $\mathrm{MAC}<21 \mathrm{~cm}$ & (1) & 1.00 & 3.50 \\
\hline $\mathrm{CC}<30 \mathrm{~cm}$ & (1) & 6.61 & 17.55 \\
\hline $\begin{array}{l}\text { Lost } \geq 3 \mathrm{~kg} \text { within } \\
\text { the last year }\end{array}$ & (2) & 14.75 & 13.80 \\
\hline \multicolumn{4}{|l|}{ Global evaluation } \\
\hline Eating alone & (1) & 15.51 & 15.96 \\
\hline $\begin{array}{l}\text { Taking } \geq 3 \text { prescribed } \\
\text { medicines }\end{array}$ & (1) & 2.88 & 11.39 \\
\hline $\begin{array}{l}\text { Encountered a } \\
\text { very sad event }\end{array}$ & (2) & 15.00 & 22.60 \\
\hline Impaired mobility & (2) & 2.97 & 4.14 \\
\hline Feel lonely most of the time & (1) & 3.43 & 4.81 \\
\hline Headaches, joints/skin sore & (1) & 11.80 & 23.30 \\
\hline \multicolumn{4}{|l|}{ Dietary parameters } \\
\hline \multicolumn{4}{|l|}{ Meals/day } \\
\hline 2 & $(0.5)$ & 3.43 & 4.62 \\
\hline 1 & (1) & 0.10 & 0.10 \\
\hline \multicolumn{4}{|l|}{ Need help in order to eat } \\
\hline Need some help & $(0.5)$ & 1.65 & 1.83 \\
\hline Need total help & (1) & 1.99 & 2.36 \\
\hline Have digestive problems & (1) & 10.81 & 15.53 \\
\hline $\begin{array}{l}\text { Appetite decreased } \\
\text { significantly }\end{array}$ & (2) & 8.52 & 8.51 \\
\hline$<1$ protein-rich food/day & (1) & 2.70 & 6.50 \\
\hline$<1$ fruit or vegetable/day & (1) & 1.79 & 0.92 \\
\hline Have $>2$ restrictive diets & (1) & 5.34 & 6.11 \\
\hline \multicolumn{4}{|l|}{ Subjective self-assessment } \\
\hline Current health is poor & (1) & 5.64 & 7.84 \\
\hline $\begin{array}{l}\text { Health not as good as } \\
\text { a year ago }\end{array}$ & (1) & 38.77 & 45.87 \\
\hline Self-perceived malnutrition & (1) & 6.91 & 8.41 \\
\hline
\end{tabular}

MAC - mid-arm circumference; CC - calf circumference; BMI - body mass index.

* See Appendix for detailed questions. 
Table 3 Pearson correlation coefficients between total nutrition risk score and the contributing parameters. All correlations listed are significant $(P<0.001)$

\begin{tabular}{lr}
\hline Parameter & \multicolumn{1}{c}{$r$} \\
\hline Age & 0.300 \\
BMI & -0.253 \\
MAC & -0.218 \\
CC & -0.325 \\
Eating alone & 0.309 \\
Feeling lonely & 0.507 \\
Encountered a very sad event & 0.491 \\
Number of long-term medicines & 0.411 \\
Poor self-assessed health status & 0.553 \\
Worsened health status compared with a year ago & 0.443 \\
Not enough food to eat & 0.216 \\
Meals per day & 0.194 \\
Poor appetite & 0.488 \\
Reduced food intake & 0.523 \\
Items of protein-rich food consumed & 0.262 \\
Items of fruits and vegetables consumed & -0.353 \\
Frequency of tea drinking & 0.257 \\
Number of dietary restrictions & 0.177
\end{tabular}

MAC - mid-arm circumference; CC - calf circumference; BMI - body mass index.

Approximately equal proportions of men and women (15.51 and $15.96 \%$, respectively) usually ate their meals alone. A much higher proportion of elderly females (11.39\%) than elderly males (2.88\%) were on three or more prescribed long-term medications. More elderly women (22.6\%) than men (15.0\%) had encountered a very sad event during the last 12 months. Similarly, more females (4.14\%) than males (2.97\%) reported impaired mobility, being unable to get around or take care of their daily routines. Results also showed that $3.43 \%$ of elderly men and $4.81 \%$ of women felt lonely most of the time. A greater proportion of females (23.30\%) than males (11.80\%) reported long-term pain such as headache,

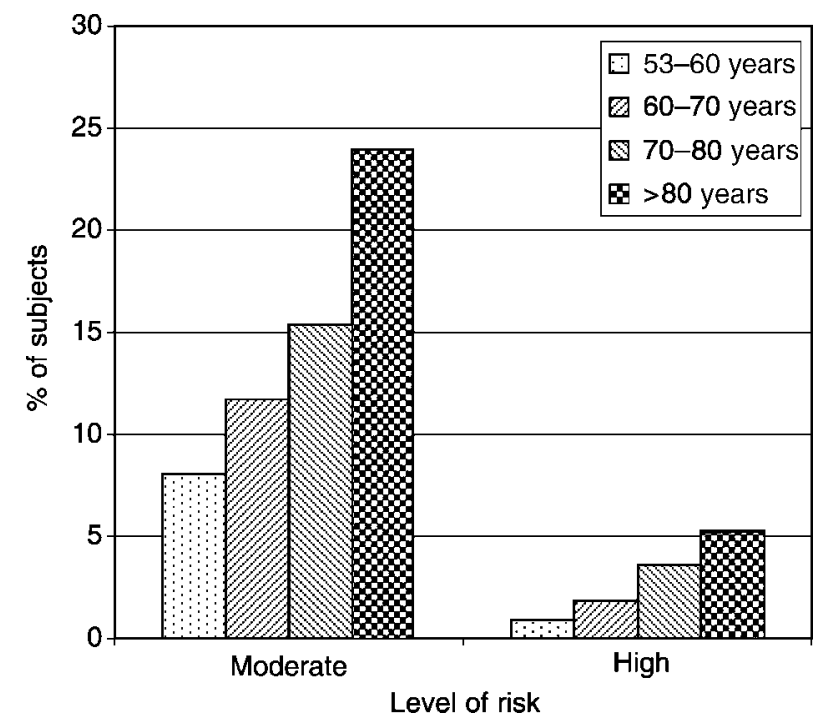

Fig. 1 Risk status of the $>53$-year-old population in Taiwan, showing the proportions of respondents considered at moderate (score $5.5-10$ ) or high (score $\geq 10.5$ ) risk of malnutrition by age group joint pain or skin sores. Only $0.51 \%$ of elderly men and $1.01 \%$ of elderly women indicated that they did not have enough food to eat. The great majority of the elderly in Taiwan ate three whole meals a day. Only 3.43\% of elderly men and $4.62 \%$ of women usually ate two meals a day and very few ( $0.10 \%$ of both men and women) ate only one meal a day. The survey also showed that $1.65 \%$ of elderly men and $1.83 \%$ of women needed some assistance, while $1.99 \%$ of elderly men and $2.36 \%$ of women needed total help, in order to eat. Again, a higher proportion of elderly women (15.53\%) than men (10.81\%) reported having oral, dental or digestive problems. Roughly equal proportions of elderly men and women (8.52 and $8.51 \%$, respectively) reported reduced food intake during the past 3 months. A larger proportion of elderly women (6.50\%) than men (2.70\%) consumed less than one item of protein-rich food per day. Only a very small proportion of men (1.79\%) and women $(0.92 \%)$ consumed less than one kind of fruit or vegetable per day. Roughly equal proportions of elderly men (5.34\%) and women (6.11\%) had two or more prescribed dietary restrictions. Among the self-evaluated items, $5.64 \%$ of elderly men and $7.84 \%$ of elderly women thought that their health was poor while relatively large proportions of elderly men (38.77\%) and women (45.87\%) felt that their health was not as good as a year ago. There were $6.91 \%$ of elderly men and $8.41 \%$ of women who thought that they had malnutrition.

The proportions of the elderly population considered at moderate and high risk of malnutrition are shown in Fig. 1. The moderate- and high-risk proportions increased with age. The proportions considered at high risk (using total risk score $\geq 10.5$ as a criterion) were $0.88,1.86,3.6$ and $5.3 \%$ for the 53-60-, 60-70-, 70-80- and $>80$-year-old populations, respectively. The proportions considered at moderate risk (total risk score 5.5-10.0) were 8.03, 11.7, 15.38 and $23.96 \%$ for the respective age ranges. The detailed distribution of risk scores is shown in Fig. 2. The proportions of elderly having a very low risk of malnutrition (score 0 or $1-2$ ) decreased with increasing age. The pattern was reversed as the level of risk was increased (risk score 3-4 and higher).

Table 3 shows the parameters that are significantly correlated with the total nutrition risk scores. Among the factors, feeling lonely, encountered a very sad event, number of long-term medications, poor self-assessed health status, worsening health status and poor appetite or reduced food intake all showed the greatest correlations with the risk scores. Age, anthropometric parameters, eating alone, not enough food to eat and number of meals per day showed moderate correlations with the total risk scores. Dietary intake indicators such as the consumption of protein-rich foods, fruit and vegetables and drinking tea all showed significant negative correlations with the total risk scores. The number of restrictive diets was also correlated with the score. 


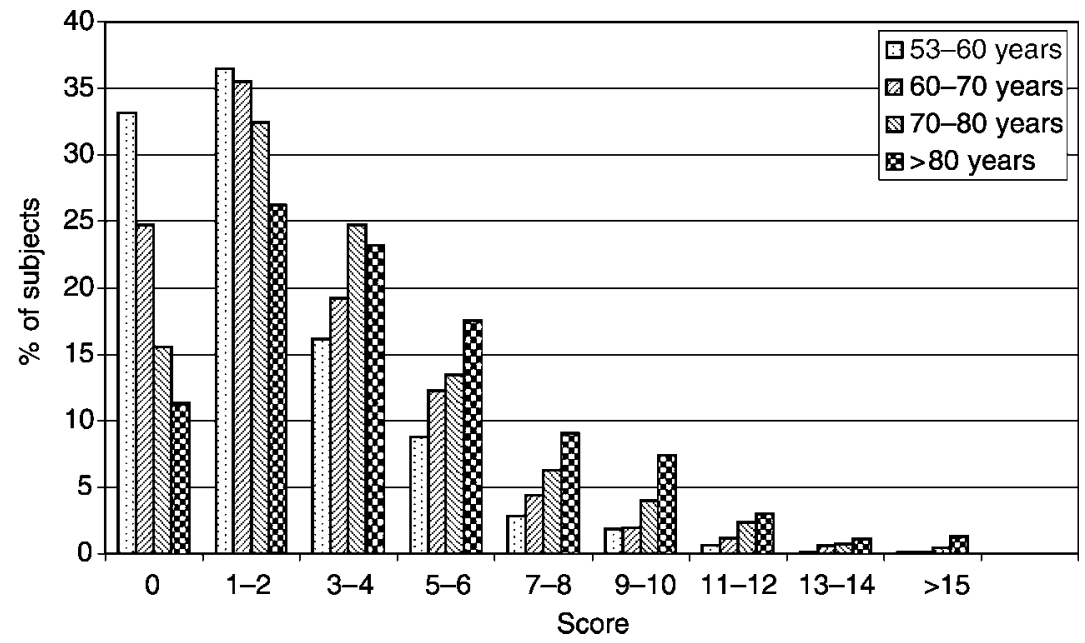

Fig. 2 Distribution of risk scores of the $>53$-year-old population in Taiwan, by age group

\section{Discussion}

\section{Response rate}

Similar to previous studies conducted by this Institute (TPIFP), the study achieved a response rate of $90.34 \%$, which is considered high for this type of study. This high success rate is attributed mainly to two factors. The primary factor is the diligent and experienced research team including the field interviewers and the field healthcare workers, who have maintained a good working relationship with the elderly subjects. The other factor is the relentless effort of the research team in locating subjects by using the nation-wide household registration system that efficiently maintains a complete record of citizens' present and past residential addresses.

\section{Antbropometrics}

Losing weight is a characteristic of advanced ageing ${ }^{16,17}$. Our data confirmed this observation. There is a downward shift of the BMI distribution in advanced ageing. The underweight proportion increased and the overweight decreased, while the normal-weight proportion maintained fairly constant with advanced ageing. Weight loss appeared to start earlier for men than for women. Overall, approximately $65 \%$ of males and $60 \%$ of females aged $>53$ years were normal-weight (defined as BMI $=19.1-$ $25.0 \mathrm{~kg} \mathrm{~m}^{-2}$ ). The proportion stayed fairly constant throughout the age ranges. On the other hand, the proportion of overweight $\left(\mathrm{BMI}=25.1-30.0 \mathrm{~kg} \mathrm{~m}^{-2}\right)$ and obese (BMI $>30.1 \mathrm{~kg} \mathrm{~m}^{-2}$ ) individuals decreased from a high of approximately 35\% in 53-60-year-old subjects to less than $20 \%$ for those subjects aged $>80$ years. In addition to BMI, MAC and CC values of the elderly also decreased with advanced ageing, supporting the observation of earlier studies that ageing is associated with a loss of fat-free mass or body muscle protein ${ }^{18-20}$. These changes support the findings of some earlier studies that weight loss is mainly due to non-fat body tissues and that the process starts earlier and is more drastic for males than for females ${ }^{20-22}$.

\section{Food availability and dietary intake}

Our results indicated that food is readily available to the elderly in Taiwan. Less than 1\% of the elderly population indicated that they did not have enough food to eat. More than $96 \%$ of the elderly ate three full meals a day, with the rest eating two. These results support the findings of a recent national nutritional and health survey of Taiwan ${ }^{23}$ that more than $95 \%$ of the $>65$-year-old population eat three meals a day. Most of the elderly (>95\%) consumed at least one kind of protein-rich food per day (could be more than one time per day) and nearly every elderly subject (approximately 99\%) consumed at least one kind of fruit or vegetable per day. However, it should be reminded that good food availability does not equate to good nutrition. Poor food selection, poor appetite, poor health or sickness, immobility, and emotional and psychological stress can singly or collectively contribute to increased nutritional risk.

\section{Prevalence of nutritional risks}

Using the criteria that a total risk score of $\geq 10.5$ indicates a high risk and a score of 5.5-10.0 a moderate risk of malnutrition, results of this study clearly showed that the proportions of subjects in these two risk categories increased with advanced ageing. The high-risk proportion increased from a low of $0.88 \%$ in 53-60-year-old subjects to a high of $5.30 \%$ in subjects aged $>80$ years. The moderate-risk proportion increased from $8.08 \%$ to $23.96 \%$ in the respective age ranges. The level of nutritional risk was significantly correlated with subjective self-evaluation parameters such as current health status $(r=0.553)$ and health condition relative to a year ago. These results suggest that subjective self-evaluation is a valuable tool in health assessment. Recent food intake changes $(r=0.523)$ and current appetite status $(r=0.488)$, both reflecting 
overall health status, also showed high correlation. Two psychological parameters, feeling lonely most of the time and encountered a very sad event, also showed high correlation with the total risk scores, suggesting that psychosocial factors have a great impact on the well-being of elderly subjects. Multiple long-term use of prescribed medicine was also highly correlated with risk score. Multiple medications most likely reflect poor health and can affect one's appetite, nutrient absorption and metabolism ${ }^{24}$. Among the nutritional factors, the intake frequency of fruits and vegetables showed the highest correlation with the total risk score $(r=0.353)$. Intake frequency of protein-rich food or staple food such as rice and wheat also showed good correlation. Among the anthropometric parameters included in this study, CC had a higher correlation with the total risk score than did BMI or MAC. The calf muscle is important in maintaining mobility. Therefore, a severely reduced calf size not only reflects poor health but could also impair one's mobility and accessibility to food.

In general, the elderly females appeared to rate their health less favourably than did elderly males. The same was true with self-rating on emotional/psychological parameters. Relatively greater proportions of females than males indicated they have the following conditions: longterm digestive problems, immobility, feeling lonely most of the time, encountering sad events (or sad feeling), poor health, worsening health condition relative to a year ago, and malnutrition. In addition, a greater proportion of females than males (16.64\% vs. $10.08 \%$ ) took two or more kinds of long-term prescribed medicine. While some of the differences may reflect factual differences, some may reflect how the two genders react or view things differently.

Similar to other nutrition-risk assessment tools, this assessment procedure adopted uniform criteria for both genders. It is conceivable that this may create some gender-related bias. For example, females generally have smaller mid-arm and calf circumferences and thus are more likely to be below the same cut-off levels. As a result, relatively more females have MAC values below $21 \mathrm{~cm}$ than do males. Similarly, $\geq 3 \mathrm{~kg}$ of body weight is a greater percentage of total body weight for most females than for males, and thus its loss would have a greater impact for female than for male subjects. Thus, some gender-related adjustments of standards seem necessary.

The questionnaire used to assess nutrition risk in the present study included 21 questions. Even with our extensive pre-study field tests, some questions appear to have somewhat overlapping meanings and some appear to have low sensitivity. Thus, further refinement of the questionnaire is useful and needed. Based on the correlation analysis, it appears that a questionnaire composed of 10-12 key questions may be adequate to assess nutritional risk in the elderly.

The questionnaire appeared to provide a simple procedure for screening for and identifying the elderly at risk of malnutrition and in need of nutritional or other interventions. Geriatric assessment (which includes nutrition-risk assessment) and intervention have been proved to produce improvements in mortality and functional status in older persons ${ }^{25}$. Even though food availability is not a significant problem in Taiwan, undernutrition still could occur owing to other reasons such as poor appetite, emotional stress or other health reasons ${ }^{26}$. The study suggests that a risk assessment questionnaire revised from the Mini Nutritional Assessment questionnaire can be effectively employed to screen for and identify the elderly individuals at risk of malnutrition in Taiwan. The availability of such a simple and non-invasive procedure will enable easy identification of the high-risk elderly for interventions, an important step leading to improving the quality of life of the elderly and saving on healthcare costs.

\section{Acknowledgements}

This study was funded by formerly the Taiwan Provincial Institute of Family Planning, now a component of the Bureau of Health Promotion of the Department of Health, the Executive Yuen, Taiwan, Republic of China. The study was conducted by the Institute (TPIFP) in collaboration with the School of Public Health of the University of Michigan, Ann Arbor, MI, USA. The authors wish to thank the hard-working field interviewers who diligently completed the personal interviews and Ms Fu-Mei Tseng who carried out the statistical analysis.

\section{References}

1 US Department of Commerce, Bureau of Census. An Aging World. International Population Reports, Series P-95, No. 78. Washington, DC: US Government Printing Office, 1987.

21989 Survey of Health and Living Status of the Elderly in Taiwan: Questionnaire and Survey Design. Comparative Study of the Elderly in Four Asian Countries. Research Report No. 1. Taichung, Taiwan/Ann Arbor, MI: Taiwan Provincial Institute of Family Planning, Population Studies Center/ Institute of Gerontology, University of Michigan, December 1989.

3 Chandra RK. Effect of vitamin and trace-element supplementation on immune responses and infection in the elderly. Lancet 1992; 340: 1124-7.

4 Chandra RK. Nutrition and immunity in the elderly. Nutrition Reviews 1992; 50: 367-71.

5 Chandra RK. Nutrition and immunity in the elderly: clinical significance. Nutrition Reviews 1995; 53: S80-5.

6 Larsson J, Unosson M, Ek AC, Nilsson L, Thorslund S, Bonjour JP. Effect of dietary supplement on nutrition status and clinical outcome in 501 geriatric patients - a randomized study. Clinical Nutrition 1990; 9: 179-84.

7 Corder LS. Compression of disability: evidence from the national long-term care survey. Nutrition Reviews 1996; 54: S9-16.

8 Egbert AM. The dwindles: failure to thrive in older patients. Nutrition Reviews 1996; 54: 225-30.

9 Guigoz Y, Vellas BJ, Garry PJ. The Mini Nutritional Assessment (MNA): a practical assessment tool for grading the nutritional state of elderly patients. In: Vellas BJ, Guigoz Y, 
Garry PJ, Albarede JL, eds. Nutrition [Supplement]. Facts and Research in Gerontology. New York: Serdi Publishing Co., 1994; 15-60.

10 Wellman NS. The Nutrition Screening Initiative. Nutrition Reviews 1994; 52: 44-7.

11 White JV, Dwyer JT, Posner BM, Ham RJ, Lipschitz DA, Wellman NS. Nutrition Screening Initiative: development and implementation of the public awareness checklist and screening tools. Journal of the American Dietetic Association 1992; 92: 163-7.

12 Posner BM, Jette AM, Smith KW, Miller DR. Nutrition and health risks in the elderly: The Nutrition Screening Initiative. American Journal of Public Health 1993; 83: 872-8.

13 Chang MC, Hermalin AI. 1996 Survey of Health and Living Status of the Middle Aged and Elderly in Taiwan. (A) Survey of those over 50-66 years of age. Elderly in Asia Research Report No. 98-49. Taichung, Taiwan: Taiwan Provincial Institute of Family Planning, April 1998.

14 Chang MC, Hermalin AI. 1996 Survey of Health and Living Status of the Middle Aged and Elderly in Taiwan. (B) Survey of those over 67 years of age. Elderly in Asia Research Report No. 98-50. Taichung, Taiwan: Taiwan Provincial Institute of Family Planning, April 1998.

15 Anon. Assessment of the hospitalized patient. In: Lee RD, Nieman DC, eds. Nutritional Assessment. Madison, WI: WCB Brown \& Benchmark Publications, 1993; 165-91.

16 Steen B, Lundgren BK, Isaksson X. Body composition at age 70, 75, 79 and 81. A longitudinal population study. In: Chandra RK, ed. Nutrition, Immunity, and Illness in the Elderly. New York: Pergamon Press, 1985; 49-52.

17 Steen B. Body composition and aging. Nutrition Reviews 1988; 46: 45-51.
18 Novak LP. Aging, total body potassium, fat-free mass, and cell mass in males and females between ages 18 and 85 years. Journal of Gerontology 1972; 27: 438-43.

19 Forbes GB, Reina JC. Adult lean body mass declines with age: some longitudinal observations. Metabolism 1970; 19: $153-63$.

20 Prothro J. Protein and amino acid requirements of the elderly. Annals of the New York Academy of Sciences 1989; 561: $143-56$.

21 Forbes GB, Reina JC. Adult lean body mass declines with age: some longitudinal observations. Metabolism 1970; 19: 653-63.

22 Flynn MA, Nolph GB, Baker AS, Martin WM, Krause G. Total body potassium in aging humans: a longitudinal study. American Journal of Clinical Nutrition 1989; 50: 713-17.

23 Department of Health, Executive Yuen. Report of the First Nutrition and Health Survey in Taiwan', 1992-1997 (NAHSIT-I). Taipei, Taiwan: Department of Health, Executive Yuen, 1998.

24 Hathcock JN. Nutrient-drug interactions. Clinics in Geriatric Medicine 1989; 3: 297-307.

25 Stuck AE, Siu AI, Wieland GD, Adams J, Rubenstein LZ. Comprehensive geriatric assessment: a meta-analysis of controlled trials. Lancet 1993; 342: 1032-6.

26 Morley JE. Nutritional assessment is a key component of geriatric assessment. In: Vellas BJ, Guigoz Y, Garry PJ, Albarede JL, eds. The Mini Nutritional Assessment (MNA), Nutrition in the Elderly, 1994/95 [Supplement 2]. Facts and Research in Gerontology, 2nd ed. New York: Serdi Publishing Co., 1995; 5-10. 
Appendix - Questionnaire* for assessing the risk of malnutrition in > 53-year-old subjects in Taiwan

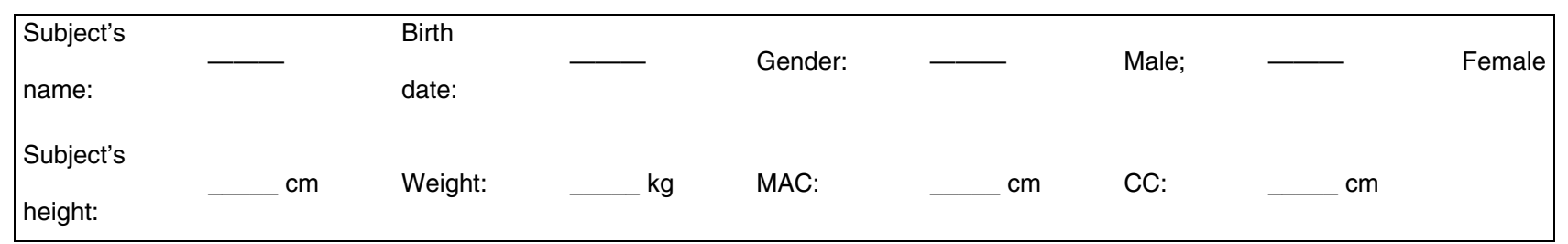

Parameter and assigned score

Anthropometric assessment

1. $B M I \leq 19 \mathrm{~kg} \mathrm{~m}^{-2}($ no $=0$, yes $=2)$

2. $M A C \leq 21 \mathrm{~cm}($ no $=0$, yes $=1)$

3. $\mathrm{CC}<30 \mathrm{~cm}(\mathrm{no}=0$, yes $=1)$

4. Have you lost more than $3 \mathrm{~kg}$, unintentionally, during the last 6 months? $(\mathrm{no}=0$, yes $=2)$

\section{Global evaluation}

5. Do you usually eat alone? (no $=0$, yes $=1$ )

6. Are you told to take three or more kinds of prescribed medicine? (no $=0$, yes $=1$ )

7. Have you encountered a very sad event within the last 12 months? $($ no $=0$, yes $=2)$

8. Do you have difficulty moving around? ( $\mathrm{no}=0$, yes $=2$ )

9. Do you feel lonely or depressed most of the time? (no $=0$, yes $=1$ )

10. Do you have long-term headache, joint pain or skin sore? (no $=0$, yes $=1$ )

\section{Dietetic assessment}

11. Do you usually have enough food to eat? (yes $=0$, no $=1$ )

12. How many meals do you usually eat a day? ( $\geq 3$ meals $=0,2$ meals $=0.5,1$ meal $=1$ )

13. Do you need assistance in order to eat? ( $\mathrm{no}=0$, need some help $=0.5$, need help $=1$ )

14. Do you have long-term digestive problems such indigestion, diarrhoea or constipation to affect your food intake? (no $=0$, yes $=1$ )

15. Has the amount of food you eat reduced significantly recently? (no $=0$, yes $=2$ )

16. Frequency of intake of protein-rich foods $(>1$ item/day $=0,<1$ item/day $=1)$

17. Frequency of intake of fruits and vegetables $(>1$ item/day $=0,<1$ item/day $=1)$

18. Number of special or restrictive diets your doctor has prescribed for you $(0$ or $1=0, \geq 2=1)$

\section{Subject evaluation}

19. Do you think you have good health? (yes $=0$, no $=1$ )

20. Compared to your health condition one year ago, is your current health the same, better or worse? (same or better $=0$, not as good $=1$ )

21. Do you think you have malnutrition? ( $\mathrm{no}=0$, yes $=1$ )

Total risk score

MAC - mid-arm circumference; CC - calf circumference; BMI - body mass index (= weight in kg divided by the square of height in $\mathrm{m}$ ). Risk levels - total risk score: $0-5.0$, low risk; $5.5-10$, moderate risk; $\geq 10.5$, high risk. 